Audiology

Neurotology
Audiol Neuroto 2012;17:121-125

DOI: $10.1159 / 000331394$
Received: June 6, 2011

Accepted: July 27, 2011

Published online: September 29, 2011

\title{
What Is the Site of Origin of Cochleovestibular Schwannomas?
}

\author{
Christof Roosli ${ }^{a}$ d Fred H. Linthicum, Jr. ${ }^{\text {b }}$ Sebahattin Cureogluc Saumil N. Merchant ${ }^{a}$ \\ ${ }^{a}$ Massachusetts Eye and Ear Infirmary, Harvard Medical School, Boston, Mass., b House Ear Institute, \\ Los Angeles, Calif., and ' Department of Otolaryngology, University of Minnesota, Minneapolis, Minn., USA; \\ ${ }^{\mathrm{d} C l i n i c}$ of Otorhinolaryngology-Head and Neck Surgery, University Hospital Zurich, Zurich, Switzerland
}

\section{Key Words}

Vestibular schwannoma $\cdot$ Histopathology, temporal bone $\cdot$ Origin · Obersteiner-Redlich zone $\cdot$ Glial-Schwann cell transition zone

\begin{abstract}
The belief that cochleovestibular schwannomas arise from the glial-Schwann cell junction has repeatedly been quoted in the literature, although there is no published evidence that supports this statement. A systematic evaluation of the nerve of origin and the precise location of cochleovestibular schwannomas using our respective archival temporal bone collections was conducted. Forty tumors were within the internal auditory canal (IAC), while 10 were intralabyrinthine neoplasms. Of the 40 IAC schwannomas, 4 arose from the cochlear nerve, and 36 from the vestibular nerve. Twentyone tumors clearly arose lateral to the glial-Schwann cell junction, while 16 tumors filled at least two thirds of the IAC, with the epicenter of the neoplasm located in the mid part or the lateral part of the IAC. Only 3 schwannomas were located in the medial one third of the IAC in the area of the glial-Schwann cell junction. We concluded that cochleovestibular schwannomas may arise anywhere along the course of the axons of the eighth cranial nerve from the glialSchwann sheath junction up until their terminations within the auditory and vestibular end organs.
\end{abstract}

Copyright $\odot 2011$ S. Karger AG, Basel

\section{KARGER}

Fax +4161306 1234 E-Mail karger@karger.ch www.karger.com
(C) 2011 S. Karger AG, Basel

Accessible online at:

www.karger.com/aud

\section{Introduction}

The nomenclature of tumors arising from the eighth cranial nerve has been inconsistent in the literature. Although in common use, the term 'acoustic neuroma' is a misnomer because this neoplasm arises from Schwann cells. It is, therefore, a schwannoma rather than a true neuroma since the latter implies a proliferating mass of nerve fibers [Merchant and McKenna, 2010]. Furthermore, the tumor more commonly arises from the vestibular rather than the acoustic or cochlear nerve. A more accurate term is 'cochleovestibular schwannoma', which is what we will preferentially use in the rest of this paper.

For most cranial and spinal nerves, neuroglial cells extend for only a fraction of a millimeter beyond their origin from the brainstem or spinal cord [Tarlov, 1937; Guclu et al., 2009]. An exception is the cochleovestibular nerve, which has glia extending for a median length of $9.75 \mathrm{~mm}$ along its course [Bridger and Farkashidy, 1980]. The zone at which the glial tissue ends and the Schwann cells begin is termed the 'glial-Schwann sheath junction', also known as the 'Obersteiner-Redlich zone' [Obersteiner and Redlich, 1895; Redlich, 1897]. This transition zone is typically located at or medial to the porus of the internal auditory canal (IAC) [Bridger and Farkashidy, 1980] (fig. 1a, b).

It is a commonly held belief that cochleovestibular schwannomas arise from the glial-Schwann sheath junction. This statement is often quoted in the literature [de

Christof Roosli, MD

Massachusetts Eye and Ear Infirmary

243 Charles Street

Boston, MA 02114 (USA)

Tel. +1 617573 5591,E-Mail christof_roosli@meei.harvard.edu 


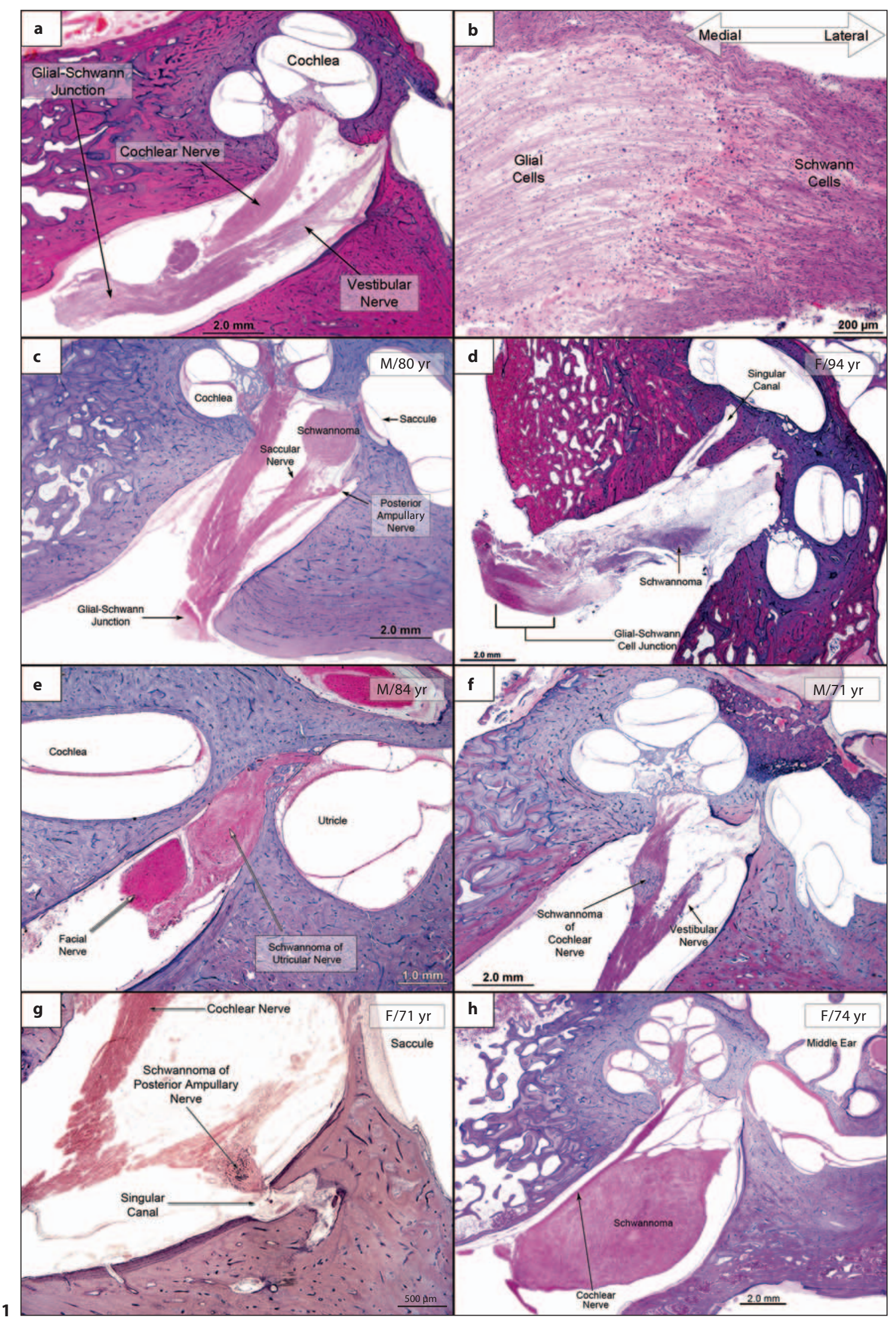


Moura, 1967; Neely et al., 1976; Curtin, 1984; Jia et al., 2008; Roche et al., 2008] and in textbooks [Kuhweide et al., 1996; Gunderson and Tepper, 2007; Bernstein and Berger, 2008; Seegenschmiedt et al., 2008]. To the best of our knowledge, there is no published evidence that supports this statement. Ascertainment of the precise site of origin of a cochleovestibular schwannoma using clinical observations is difficult. Tumors that lead to surgery often fill the IAC and have grown to a size where it is not possible to determine the tumor's origin with respect to the glialSchwann junction. The variability in the location of the glial-Schwann junction also makes it difficult to identify its exact relation to the tumor without histopathologic investigation even in small tumors. The resolution of MRI is not good enough to determine the glial-Schwann junction.

Anecdotal otopathologic observations [Henschen, 1915; Skinner, 1929; Xenellis and Linthicum, 2003] have indicated that many of these tumors originate lateral to the glial-Schwann sheath junction. The purpose of this study was to conduct a systematic evaluation of the nerve of origin and the precise location of cochleovestibular schwannomas using our respective archival temporal bone collections.

\section{Material and Methods}

Archival temporal bones with a diagnosis of sporadic cochleovestibular schwannoma within the collections at the Massachusetts Eye and Ear Infirmary, the House Ear Institute, the University of Minnesota (all USA) and the University Hospital of Zurich (Switzerland) were examined. The temporal bones had been processed for light microscopy using the standard method of fixation in formalin, decalcification using trichloroacetic acid or ethylenediaminetetraacetic acid, embedding in celloidin, serial sectioning in the horizontal plane at a section thickness of $20 \mu \mathrm{m}$, and staining of every tenth section using hematoxylin and eosin [Merchant, 2010]. Both symptomatic and occult cases of cochleovestibular schwannoma were included. Sections of each case were examined to determine the nerve of origin of the tumor and the site of origin in relation to the glial-Schwann junction. The institutional review boards of our respective institutions approved the study.

Fig. 1. a, b Low- and high-power views of the glial-Schwann cell junction from a 53-year-old man. c-g Examples of small schwannomas within the IAC, arising in the mid or lateral parts of the IAC. In $\mathbf{c}$ and $\mathbf{d}$, the schwannomas are seen to be clearly lateral to the glial-Schwann cell junction. The schwannomas in e-g were also arising lateral to the glial-Schwann cell junction, as determined by examination of serial sections. $\mathbf{h}$ Example of a schwannoma filling the medial two thirds of the IAC. The epicenter of the tumor is in the mid portion of the IAC.

Origin of Cochleovestibular

Schwannomas
Table 1. Nerve of origin of 50 cochleovestibular schwannomas (n)

\begin{tabular}{|c|c|c|c|}
\hline \multicolumn{3}{|l|}{ Cochlear nerve } & \multirow{2}{*}{12} \\
\hline IAC & & 4 & \\
\hline Cochlea & & 8 & \\
\hline Vestibular nerve & & & 38 \\
\hline IAC & & 36 & \\
\hline Trunk & 13 & & \\
\hline Superior & 13 & & \\
\hline Inferior & 10 & & \\
\hline Intralabyrinthine & & 2 & \\
\hline
\end{tabular}

Table 2. Location of schwannomas within IAC (n)

\begin{tabular}{llll}
\hline & $\begin{array}{l}\text { Tumor in } \\
\text { one third }\end{array}$ & $\begin{array}{l}\text { Tumor in } \\
\text { two thirds }\end{array}$ & $\begin{array}{l}\text { Tumor in } \\
\text { all thirds }\end{array}$ \\
\hline $\begin{array}{l}\text { Medial third } \\
\text { Middle third }\end{array}$ & 3 & 4 & 11 \\
Lateral third & 4 & 1 & \\
\hline
\end{tabular}

\section{Results}

There were a total of 97 ears with sporadic cochleovestibular schwannoma. Of these, the nerve and site of origin could not be ascertained in 48 cases because of surgical resection. There were 50 schwannomas from 49 ears where information about the site of origin could be obtained, and these cases were subjected to further analysis. There were 24 males and 25 females, with ages ranging from 25 to 100 years (mean: 75 years).

Table 1 describes the nerve of origin. The tumor arose from the vestibular nerves or one of its branches in 38 ears (76\%), while 12 (24\%) arose from the cochlear nerve. There was an approximately equal distribution between sites of origin within the vestibular nerve trunk $(n=13)$, the superior vestibular nerve $(n=13)$ and the inferior vestibular nerve $(\mathrm{n}=10)$.

Table 2 shows the distribution of tumors with respect to the glial-Schwann junction in the 40 tumors located within the IAC. In 3 ears (7.5\%), the tumor could have arisen from the glial-Schwann junction because the neoplasm was located in the medial third of the IAC. In 16 ears (40\%), the schwannoma filled at least two thirds of the IAC, but since the epicenter of the tumor was in the mid portion of the canal or in the lateral part of the canal, it was unlikely that the tumor had arisen from the glialSchwann junction. In another 21 ears (52.5\%), the tumor

Audiol Neuroto 2012;17:121-125 
clearly arose from a location that was lateral to the junction; these schwannomas were small enough that the junction was clearly seen as separate from the entire tumor. Examples of tumors at various locations are shown in figure $1 \mathrm{c}-\mathrm{h}$.

\section{Discussion}

The results of the present study clearly demonstrate that the majority of sporadic cochleovestibular schwannomas originate lateral to the glial-Schwann junction. There are no published data to support the commonly held belief that cochleovestibular schwannomas arise from the glial-Schwann junction. One might ask, then: how did this belief come up and how did it become established in the literature?

Our review of the early writings on the subject of the origin of cochleovestibular schwannoma suggests a possible explanation. In the early part of the twentieth century, there was a debate as to whether these tumors arose from neuroglial cells [Verocay, 1910; Henschen, 1915], from fibrous nerve tissue [Henschen, 1915; Cushing, 1917; Antoni, 1920] or from Schwann cells [Skinner, 1929] of the eighth cranial nerve. The tumors encountered in those days were uniformly large ones where the site of origin could not be determined at the time of surgical resection. Furthermore, light microscopic histological study alone could not conclusively prove the cellular origin of the tumor. It was not until the 1960s when electron microscopic studies showed morphologic characteristics typical of Schwann cells that these tumors were recognized as being schwannomas [Luse, 1960; Raimondi et al., 1962; Hilding and House, 1965].

The renowned neurosurgeon Harvey Cushing, in a review of the subject in 1917, concluded that the histogenesis of these tumors depended on connective tissue and neuroglia, and that these tumors possibly arose from tissue rests near the zone of transition [Cushing, 1917]. It is conceivable that the debate concerning the cells of origin (glial vs. endoneurium vs. Schwann cells), along with opinions such as those articulated by Cushing, gave rise to the erroneous assumption that these tumors arose from the junction. The erroneous assumption then had a life of its own in the literature.

The eighth cranial nerve has a higher propensity for schwannoma growth compared to other cranial nerves since cochleovestibular schwannomas constitute over $90 \%$ of all schwannomas arising from cranial nerves [Nager, 1984]. Our study shows that a sporadic cochleo- vestibular schwannoma may arise from Schwann cells anywhere along the course of the axons of the eighth cranial nerve from the glial-Schwann sheath junction up until their terminations within the auditory and vestibular end organs. When such a tumor arises from a nerve sheath within the bony labyrinth, the result is an intralabyrinthine schwannoma, whereas the result is a more traditional cochleovestibular schwannoma when it arises within the IAC. The reason or reasons underlying the enhanced susceptibility of the vestibular and cochlear nerves to neoplastic transformation awaits further research.

There is a clear propensity for Schwann cells of the vestibular nerve to give rise to these tumors as we observed a 3.2:1 ratio between the vestibular and cochlear nerves. Contrary to others [Komatsuzaki and Tsunoda, 2001; Khrais et al., 2008] who found an incidence of origin of $84-92 \%$ for the inferior vestibular nerve, we did not find a clear preference for the inferior versus superior vestibular nerve. The difference may be due to differing patient groups. While we investigated the nerve of origin in both occult and symptomatic cases using histological sections, Khrais et al. [2008] and Komatsuzaki and Tsunoda [2001] defined the nerve of origin in symptomatic cases at the time of surgery.

\section{Conclusions}

Cochleovestibular schwannomas (acoustic neuromas) arise from Schwann cells ensheathing the axons of the eighth cranial nerve anywhere from the glial-Schwann junction up until the nerve terminations within the auditory and vestibular sense organs. Most tumors originate lateral to the glial-Schwann sheath junction. Further, these tumors arise from the vestibular nerve or one of its branches in the majority of instances.

\section{Acknowledgments}

The authors wish to thank Jon Pack for the photomicrographs. This study was supported by funding from NIH (National Institute on Deafness and Other Communication Disorders) grant No. U24DC011943. 


\section{References}

Antoni NRE: Über Rückenmarkstumoren und Neurofibrome. München, JF Bergmann, 1920.

Bernstein M, Berger MS: Neuro-Oncology, ed 2. New York, Thieme, 2008.

Bridger MW, Farkashidy J: The distribution of neuroglia and Schwann cells in the 8 th nerve of man. J Laryngol Otol 1980;94:1353-1362.

Curtin HD: CT of acoustic neuroma and other tumors of the ear. Radiol Clin North Am 1984;22:77-105.

Cushing H: Tumors of the Nervus Acusticus and the Syndrome of the Cerebellopontile Angle. Philadelphia, WB Saunders, 1917.

$\checkmark$ de Moura LF: Inner ear pathology in acoustic neurinoma. Arch Otolaryngol 1967;85:125133.

- Guclu B, Meyronet D, Simon E, Streichenberger N, Sindou M, Mertens P: Structural anatomy of cranial nerves (V, VII, VIII, IX, X) (in French). Neurochirurgie 2009;55:92-98.

Gunderson LL, Tepper JE: Clinical Radiation Oncology. Philadelphia, Elsevier Churchill Livingston, 2007.

Henschen F: Zur Histologie und Pathogenese der Kleinhirnbrückenwinkeltumoren. Arch Psychiatr Nervenkr 1915;56:20-122.

-Hilding DA, House WF: 'Acoustic neuroma': comparison of traumatic and neoplastic. J Ultrastruct Res 1965;12:611-623.
Jia H, Marzin A, Dubreuil C, Tringali S: Intralabyrinthine schwannomas: symptoms and managements. Auris Nasus Larynx 2008;35: 131-136.

Khrais T, Romano G, Sanna M: Nerve origin of vestibular schwannoma: a prospective study J Laryngol Otol 2008;122:128-131.

Komatsuzaki A, Tsunoda A: Nerve origin of acoustic neuroma. J Laryngol Otol 2001;115 376-379.

Kuhweide R, Casselman JW, Ampe W: Intralabyrinthine schwannomas; in Sterkers JM, Charachon R, Sterkers O (eds): Acoustic Neuroma and Skull Base Surgery. Amsterdam, Kugler, 1996, pp 177-179.

Luse SA: Electron microscopic studies of brain tumors. Neurology 1960;10:881-905.

Merchant SN: Methods of removal, preparation and study; in Merchant SN, Nadol JB (eds) Schuknecht's Pathology of the Ear, ed 3. Shelton, PMPH USA, 2010, pp 3-51.

Merchant SN, McKenna MJ: Cochleovestibular schwannoma (acoustic neuroma); in Merchant SN, Nadol JB (eds): Schuknecht's Pathology of the Ear, ed 3. Shelton, PMPH USA, 2010, pp 492-494.

Nager GT: Neurinomas of the trigeminal nerve. Am J Otolaryngol 1984;5:301-333.

Neely JG, Britton BH, Greenberg SD: Microscopic characteristics of the acoustic tumor in relationship of its nerve of origin. Laryngoscope 1976;86:984-991.
Obersteiner H, Redlich E: Über Wesen und Pathogenese der tabischen Hinterstrangserkrankungen. Arbeit Neurol Inst Wien. Wien, 1895.

Raimondi AJ, Mullan S, Evans JP: Human brain tumors: an electron-microscopic study. J Neurosurg 1962;19:731-753.

Redlich E: Die Pathologie der tabischen Hinterstrangserkrankungen. Ein Beitrag zur Anatomie und Pathogenese der Rückenmarkshinterstränge. Jena, 1897.

Roche PH, Bouvier C, Chinot O, FigarellaBranger D: Genesis and biology of vestibular schwannomas. Prog Neurol Surg 2008;21: 24-31.

Seegenschmiedt MH, Makoski HB, Trott KR, Brady LW: Radiotherapy for Non-Malignant Disorders. Berlin, Springer, 2008.

Skinner HA: Origin of acoustic nerve tumors. Br J Surg 1929;16:440-463.

Tarlov IM: Structure of the nerve root. II. Differentiation of sensory from motor roots: observations on identification of function in roots of mixed cranial nerves. Arch Neurol Psychiatry 1937;37:1338-1355.

Verocay J: Zur Kenntnis der 'Neurofibrome'. Beitr Pathol Anat 1910;49:1-68.

Xenellis JE, Linthicum FH Jr: On the myth of the glial/Schwann junction (ObersteinerRedlich zone): origin of vestibular nerve schwannomas. Otol Neurotol 2003;24:1. 